\title{
JACOTOT-RANCIÈRE OU A DISSONÂNCIA INAUDITA DE UMA PEDAGOGIA (FELIZMENTE) PESSIMISTA
}

\author{
CARLOS SkLIAR*
}

\begin{abstract}
RESUMO: Este artigo tem a pretensão de conversar com o livro $O$ mestre ignorante, de Jacques Rancière, mas não o de resenhá-lo, quer dizer, não o de dar explicaçôes sobre o seu conteúdo e sobre as suas tanto prováveis quanto improváveis finalidades educativas. Para tal objetivo, resgato a leitura de alguns dos princípios filosóficos - dentre eles: a inversão da lógica da explicação, o malefício da compreensão, a pedagogia como tradução e contra-tradução, e a lição do poeta - os quais, como dissonâncias pedagógicas, parecem ter caracterizado a aventura e a experiência intelectual de Joseph Jacotot, um pedagogo francês do início do século XIX.
\end{abstract}

Palavras-chave: Explicação. Compreensão. Embrutecimento. Emancipação. Poética. Pedagogia.

\section{JACOTOT/RANCIÈRE OR THE INCREDIBLE DISSONANCE OF A (FORTUNATELY) PESSIMISTIC PEDAGOGY}

\begin{abstract}
This paper aims to dialogue with Jacques Ranciere's The ignorant schoolmaster. It does not aim to review it, nor to give explanations concerning its content and its both probable and improbable educational goals. With this as my aim, I rescue some philosophical principles (an inversion of the logic of explanation, the maleficity of comprehension, translation and counter-translation, the lesson of the poet) that, like other pedagogical dissonance, characterize the pedagogical adventure of a French pedagogue at the beginning of XIX century-Joseph Jacotot.
\end{abstract}

Key words: Explanation. Comprehension. Diminution. Emancipation. Poetics. Pedagogy.

Professor do Programa de Pós-Graduação em Educação da Universidade Federal de Rio Grande do Sul (UfRGS). E-mail: skliar@piaget.edu.ufrgs.br 
$\mathscr{P}$

retendo, nestas poucas, provisórias e desordenadas notas ser capaz de prestar a minha homenagem a um livro - $O$ mestre ignorante -, falar da minha sedução por um pedagogo do início do século XIX Joseph Jacotot - e expressar a minha gratidão por um autor contemporâneo - Jacques Rancière - que o resgatou da obscuridade das falsas e indignas memórias.

Procurarei para esse objetivo utilizar uma linguagem apropriada à natureza do próprio texto em questão; uma linguagem parecida àquela que provém da ética e da estética do aforismo.

A linguagem de aforismo é uma das questões que mais têm me chamado a atenção no estilo do texto de Rancière, pois frases como "tudo está em tudo", ou "compreender é a causadora de todo o mal", ou "o único erro seria tomar nossas opiniōes como verdades", ou "quem não conhece a verdade busca por ela", ou ainda "é o explicador que tem necessidade do incapaz" - para citar alguns exemplos - remetem o leitor a uma leitura diferente, que difere de outras leituras e de outras escritas.

Do mesmo jeito que o livro de Rancière, o aforismo não deveria ser um objeto de compreensão, ao menos não no sentido que a moral e/ ou a ética o pretendem. Deve ser, isso sim, olhado, tocado, sentido, ou bem nada. Como o livro de Rancière, como a aventura intelectual de Jacotot, como a pedagogia mesma.

O livro, Rancière mesmo, e Jacotot são, sem lugar a dúvidas, uma rara junção de aventuras intelectuais transformadas em sutis e ambíguos aforismos. Nos deixam, a nós leitores de poucas palavras, no meio de uma sombra e de um turbilhão de novas e velhas idéias, e cuja leitura não pode ser uma rápida tradução em discurso pedagógico rançoso, em reforma educativa etérea, em simples mudança curricular.

E ainda que isto ressoe como uma contradição em relação ao texto com o qual pretendo conversar - pois nada ou muito pouco da diferença parece respirar nas suas páginas - temos aqui a oportunidade de ler um texto diferente e de sermos diferentes ao lermos o texto. Sermos outros na leitura e outros na escrita. E, somente se for o caso, se houver a necessidade, sermos, todavia, outros na pedagogia.

\section{II}

Em tempos estes onde pouco se homenageia e muito se censura; em tempos estes onde pouco seduzimos e pouco nos deixamos seduzir 
pela palavra dos outros; em tempos onde vale mais a impiedosa e vulgar crítica, que a gratidão pelo que se oferece sem pedir nada em troca, me disponho então a homenagear, a me deixar seduzir e a expressar a minha gratidão para $O$ mestre ignorante, por Joseph Jacotot, e por Rancière.

Uma homenagem a um livro escrito em três tempos - o tempo de Jacotot, o tempo de Rancière e o meu tempo - acerca da história de uma pedagogia inaudita e/ou pessimista, o relato de uma aventura intelectual, a revelação de um acontecimento inesperado.

Um livro que (me) produz, entretanto, a desolação daquilo que tem sido pensado como o habitual e o natural pedagógico - e por isso mesmo incapaz de ser removido - quanto a convicção de que as extravagâncias educativas são muito mais promissórias que a metátese das reformas ordenadamente insípidas dos ministérios.

Um livro que é como um tumultuoso espelho e que retrata tanto o que temos feito da pedagogia e o que a pedagogia tem feito conosco, quanto reflete o que não temos feito da pedagogia e o que a pedagogia não tem feito conosco.

Um livro que fala do horror da pretensão do conhecimento, do tédio da explicação e da compreensão banal, e que diz respeito à ambivalência apaixonada pela própria língua, pela tradução, pelas inteligências, pela emancipação e pela lição dos poetas, a lição da literatura, a lição da arte. Um livro que não nós deixa indiferentes, pois a sua miragem parece destecer o sem sentido da nossa pedagogia.

E expresso aqui a minha gratidão para o pedagogo Joseph Jacotot, um revolucionário na França de 1789, exilado depois nos Países Baixos, ao se restaurar a monarquia dos Bourbons, e leitor de literatura francesa na Universidade de Louvain.

Um pedagogo que em 1818 pretendeu se afastar do cotidiano dos seus trinta anos de experiência pedagógica ao se deparar com um grupo de estudantes, a maioria dos quais não sabia o francês; um pedagogo desacomodado, desajeitado pela impossibilidade da transmissão, da explicação e da tranqüilizadora e aparente compreensão, e que ignorava por completo o idioma holandês dos seus alunos.

Um pedagogo que não quis apreender a língua dos seus alunos e que, ainda alheio à imposição de um falso consenso, utilizou a sua inicial perplexidade para ir na busca de alguma coisa em comum que o reunisse com eles, acreditando - talvez ingenuamente - que desse modo a lei da língua, a lei do mestre, a lei da explicação e/ou a lei da sua palavra não acabariam por ferir e apagar as furiosas e sensíveis dessemelhanças entre eles. 
Um pedagogo que quis não embrutecer aos seus alunos com as infinitas explicaçōes sem origem e sem porvir. E que pensou, antes de mais nada, na possibilidade de emancipar as suas inteligências, em igualálas - em fazê-las iguais? - e não em domesticá-las nem obrigá-las a uma fútil compreensão de uma fútil explicação.

Um pedagogo cujas razões parecem sempre ter fugido dos presídios metodológicos, mas não de uma crescente e sistemática atitude filosófica diante dos fatos pedagógicos. As suas questōes, as suas perguntas, os seus dilemas se nos apresentam já não como passos calculados de uma seqüência técnica, mas como dolorosas e vigilantes inquietaçōes filosóficas. Inquietaçōes filosóficas estas, como todas as outras, que precisam manter-se vivas no coração das perguntas e não ser abandonadas na indiferença das rápidas respostas.

E a sedução de um autor, Rancière, que a cada página exorciza o corpo do Jacotot até fazê-lo vivo e percebido pelas nossas vidas, até fazêlo voz própria em meio da ordem e da desordem da sua e da nossa época.

Um autor que não precisou profanar a inscrição do túmulo de Jacotot para nos narrar uma história igualmente profanada e que, pelo contrário, fez jus às virtudes e aos defeitos do pedagogo.

Ele não pretende nos ensinar uma história, no sentido que não há uma lição a apreender, mas nos deixa em solidão com aquela inscrição: "Creio que Deus criou a alma humana capaz de se instruir por si própria, e sem mestres" (Rancière, 2002, p. 143).

Um autor que recupera uma história para fazê-la novamente presente, para não esquecer, e - como o próprio Rancière nos diz - para não continuar edificando de qualquer forma, impunemente, cegamente, escolas, programas e pedagogias. Um autor que ao reconstruir a história de uma dissonância inaudita nos faz lembrar linha trás linha a consonância tediosa da pedagogia dos nossos dias.

Um autor que aposta fortemente na idéia de igualdade, da coisa em comum, do que é e o que deve ser para todos igual e que acredita que igualdade e inteligência são e devem ser sinônimos. E que desde esse prisma, nesse prisma, sofre a tensão constante da sua ambigüidade entre o ideal de igualdade e a prática do igualitarismo.

Que estas poucas, provisórias e desordenadas notas sejam então a mais simples homenagem, a maior gratidão possível, a mais pura sedução em relação a um livro, a um pedagogo e a um autor que, certamente, não nos deixarão conciliar tão facilmente a nossa vida com a nossa pedagogia. 
Jacotot e Rancière nos dizem que é preciso inverter a lógica da explicação, do sistema explicador da pedagogia, da pedagogia que é somente explicação: "A explicação não é necessária para socorrer uma incapacidade de compreender. É, ao contrário, essa incapacidade (...). É o explicador que tem necessidade do incapaz, e não o contrário, é ele que constitui o incapaz como tal" (idem, ibid., p. 20).

Deste modo, a explicação não é outra coisa que a invenção da incapacidade do outro. Explica-se, pois se tem criado com antecedência um incapaz que precisa da explicação. A invenção da incapacidade do outro é o que permite o nascimento da figura do explicador. O mestre é esse explicador que tem inventado ao incapaz para justificar a sua própria explicação. Assim sendo, o explicador e o incapaz constituem o binômio inseparável de todas as pressuposiçōes pedagógicas, atuais e passadas.

Não explicarás, resulta assim ser um dos primeiros mandamentos do mestre Jacotot. Ou quiçá, uma das suas primeiras e mais ressonantes dissonâncias pedagógicas.

Todavia, o não explicarás é muito mais do que um mandamento ou uma simples dissonância: trata-se de uma forma de pensar o pensamento, de transmitir a transmissão pedagógica, e não uma explicação voltada para explicar, tautologicamente, a explicação. O que isso significa? Explicar é um monstro de mil faces, cuja finalidade parece ser a de diminuir o outro através dos terrores das palavras; ele cria a todo momento a sensação de que o corpo do mestre aumenta de tamanho na mesma proporção que se faz diminuto o corpo do aluno. E na medida em que o mestre aumenta a extensão da sua explicação, o corpo do aluno vai ficando cada vez menor: é "empequenecido" pela explicação; a explicação é, então, um constante processo de "empequenecimento" de outro ou, nas palavras de Rancière: o embrutecimento do outro.

O aluno é alguma coisa que precisa de explicações. Ele mesmo tem que ser explicado pela explicação do mestre. Ele não pode se explicar a si próprio, senão pela explicação cotidiana, seriada e/ou ciclada e sistemática do mestre.

E o mestre tem sido formado na arte, ou melhor dizendo, na técnica da explicação; e após a sua formação ele continua pensando na estética implacável da sua explicação.

Porém, a explicação na qual tem sido formado e a qual continua procurando com desesperação não explica nada ou talvez explica a sua própria explicação, em ritmo monótono, insulso. 
A lógica da explicação perpetua-se até o infinito, mas não no sentido progressivo; muito pelo contrário: "comporta, assim, o princípio de uma regressão ao infinito: a reduplicação das razôes não tem jamais razão de se deter" (idem, ibid., p. 18).

A pedagogia perpetua e coisifica assim a relação entre uma explicação e uma compreensão que the segue como uma sombra e que lhe deve ser equivalente, idêntica, como um decalque.

A explicação é propriedade exclusiva do mestre; entretanto, a compreensão é uma propriedade provisória do aluno. Entre os dois mecanismos - explicação/compreensão - instala-se, para sempre, a arte da acabar com as distâncias. A distância entre dois sujeitos, entre duas inteligências. $\mathrm{O}$ mestre explicador abole de uma vez essa distância, a reabsorve no seio de sua palavra.

A pedagogia, para Jacotot, deve se subtrair à explicação, deve ficar órfã da ordem da explicação, deve eliminar a todo poderosa presença do explicador, deve deixar de explicar.

É preciso, então, inverter as lógicas da explicação: a lógica de inventar o outro incapaz, e a lógica conseqüente, porém simultânea, do ato de explicar. Qual seria, então, a primeira frase de Jacotot, a frase que daria início ao sentido da pedagogia? Eis ela: "É preciso que eu lhes ensine que nada tenho a ensinar-lhes" (idem, ibid., p. 27).

Ensinar o que não se tem a ensinar. Essa é a tarefa do mestre ignorante. Essa é a liçãoo (felizmente) pessimista de Jacotot.

\section{IV}

Não compreenderás parece surgir como o segundo mandamento ou a segunda dissonância pedagógica que nos apresenta Jacotot.

A compreensão tem sido pensada, pelo geral, como um movimento da razão; como o movimento último da razão; como a positividade de um movimento pelo qual alguma coisa temos já assimilado, capturado, sintetizado, ordenado, e que estamos prestes a dar a conhecer, a oferecer e oferendar, finalmente, aos outros.

A compreensão, assim pensada, é um ato individual de possessão, um egoísmo de uma razão auto-satisfatória, a outra face - não muito diferente - desse monstro que é a explicação.

Mas Jacotot e Rancière pensam exatamente o contrário: a compreensão é de uma natureza maléfica, pois fere à razão, a interrompe, a deixa sem mobilidade, quebra a sua insistente fragilidade, a ordena de uma vez e para sempre. 
Compreender é o início do fim. Diz Rancière: "Compreender é a causadora de todo o mal. É ela que interrompe o movimento da razão, destrói sua confiança em si, expulsa-a de sua via própria, ao quebrar em dois o mundo da inteligência (...)" (idem, ibid., p. 21).

Não há nada para explicar. Não há nada para compreender?

Se a explicação deixa ao mestre numa posição de superioridade no jogo das dessemelhanças, então a compreensão será sempre essa posiçāo necessariamente inferior que ocupará $\mathrm{o}$ aluno. $\mathrm{O}$ mestre explica, o aluno compreende. Eis a geometria de uma pedagogia embrutecedora.

Compreender já não é, então, um ato da razão, nem um movimento do pensar, senão a captura definitiva do aluno por parte da explicação do mestre: "compreender significa, para ele, compreender que nada compreenderá, a menos que lhe expliquem" (idem, ibid., p. 21).

É assim que a pedagogia nos é dada: primeiro passo, a explicação; segundo passo, a compreensão; terceiro passo, a re-explicação; quarto passo, creio imaginar, a maior desolação imaginável, para o mestre e para o aluno.

Forma-se ao mestre para explicar a incapacidade do aluno e formase ao aluno incapaz que tem que compreender, inutilmente, a explicação do mestre. Todo aperfeiçoamento na direção de fazer compreender "se torna [nos diz Rancière] um progresso no embrutecimento" (idem, ibid., p. 21).

Mas o mestre ignorante anula, numa operação pedagógica única e singular, tanto a explicação como o entendimento do outro. Dissocia uma coisa da outra. Explica que não tem nada para explicar e os alunos compreendem que não têm nada para compreender.

Não há explicações melhores nem piores, pois não há explicação. Não há compreensão melhor ou pior, pois não há compreensão. Dessa forma, o que é mais importante ainda, já não há alunos incapazes, diminutos, pequenos, incompletos, inferiores. E não há, também, mestres sábios que não fazem outra coisa que assimilar a inteligência, o corpo e a palavra do outro na sua própria inteligência, no seu próprio corpo, na sua própria palavra: "O explicador é aquele que impõe e abole a distância, que a desdobra e que a reabsorve no seio de sua palavra" (idem, ibid., p. 19).

\section{V}

Colocados sob suspeita os dois princípios mais pétreos da nossa pedagogia - a explicação do mestre, a compreensão do aluno - faz-se necessário agora retornar, talvez com maior intensidade, para uma pergunta anterior: se a pedagogia não é o ato de explicar, nem tem como finalidade a compreensão, o que é que inaugura a relação do mestre com os 
seus alunos? Qual seria a primeira inquietação, a primeira sílaba, o primeiro movimento? Como se inicia aquilo que chamamos de pedagogia?

Para Rancière, é necessário saber, antes de mais nada, se o ato de receber a palavra do mestre é um testemunho de igualdade ou de desigualdade. Neste sentido, o propósito da pedagogia deveria ser aquele de não fazer de duas inteligências uma inteligência só. Pois há embrutecimento quando se liga uma inteligência a uma outra inteligência. $\mathrm{O}$ embrutecimento resulta ser, assim, a coincidência entre inteligências: "Não há inteligência onde há uma agregação, ligadura de um espírito a outro espírito" (idem, ibid., p. 43). O propósito da pedagogia é aquele de poder ensinar o que se ignora, ao mesmo tempo em que o outro possa utilizar a sua própria inteligência.

Lembremos, então, para tentar responder às questôes anteriores, qual era a situação originária do mestre Jacotot e dos seus alunos em 1818.

Jacotot não sabia a língua dos alunos. Os alunos não sabiam a língua de Jacotot. $\mathrm{O}$ ato de receber a palavra do mestre era impossível. Nada podia ser explicado, nada podia ser compreendido. A pergunta anterior de Rancière talvez não faça sentido: não há desigualdade nem igualdade. Há diferenças. Diferenças de diferenças. Diferenças que diferem cada vez mais.

$\mathrm{O}$ outro fala uma língua diferente do mestre, o mestre fala uma outra língua diferente daquela do aluno. Mas o mestre Jacotot era o estrangeiro. A sua língua era a língua estrangeira. A pergunta, então, já não é mais se receber a palavra do mestre é um ato de igualdade ou desigualdade, mas, ao meu ver, outras bem diferentes: como é possível responder à questão de quem é o outro? Qual é a língua que se torna a mesmice da pedagogia e qual a língua que advém como língua do outro?

Hoje em dia, em situações parecidas, cairíamos na armadilha da imposição da nossa língua e de considerar o outro como sendo a figura única do ser estrangeiro. Caberia a ele, a esse outro, a esse estrangeiro, o primeiro movimento da pedagogia. É ele que tem de nos pedir acolhimento, hospedagem, educação, explicações e deve fazê-lo obrigatoriamente na nossa única língua, quer dizer, na língua de quem acolhe, de quem oferece hospedagem (Derrida, 1997).

E o mestre Jacotot, nos primórdios do século XIX, sentiu na pele toda a ambigüidade e a ambivalência em relação a esta questão.

Recusou-se à absorção definitiva do outro, mas não se deixou seduzir pela língua do outro. Negou-se a impor um consenso fictício, mas impôs um consenso material da língua francesa. Desistiu de fazer do francês a língua inicial, mas concentrou todas as suas energias em fazer do francês a língua "final". Procurou, é verdade, o laço mínimo de 
uma coisa em comum, mas ao fazê-lo ignorou o laço do outro com a sua própria alteridade. Não se serviu do francês para falar com os seus alunos, mas precisou sim de um intérprete para que os seus alunos lhe falassem, se fizessem ouvir, lhe contassem, lhe narrassem.

Jacotot encontrou essa coisa comum na edição bilíngüe do Telêmaco. $\mathrm{O}$ livro foi para ele esse laço mínimo a partir do qual sugeriu aos seus alunos que aprendessem o texto francês. Não se tratava de nenhum princípio metodológico de ensino, mas, ao invés disso, era uma experiência filosófica: se tudo está em tudo e se o livro é isso tudo, os alunos poderiam aprender tudo sem a necessidade de nenhum tipo de explicação sobre os primeiros elementos da língua francesa, sejam eles ortográficos, gramaticais etc.

Esta "descoberta" de Jacotot da coisa em comum poderia ser pensada em três planos em aparência diferentes: de um lado, a utilização do livro o que é dizer, dos livros, da literatura - como uma totalidade em si. No livro, nos livros encontram-se à disposição todos os elementos necessários para a compreensão: bastam, então, as palavras do Telêmaco para falar do Telêmaco. E bastam as palavras do Telêmaco, também, para adivinhar outras questôes: bastam as palavras em francês para compreender o francês, bastam as palavras do livro para adivinhar a história, a geografia etc.: "Todo conhecimento de si como inteligência está no domínio de um livro, de um capítulo, de uma frase, de uma palavra” (Rancière, op. cit., p. 37).

$\mathrm{O}$ que Jacotot talvez não percebeu - e Rancière também não - é que essa sua primeira descoberta estava sendo só parcialmente formulada: bastam, é verdade, as palavras do Telêmaco; mas elas bastam porque existe a língua do outro. Foi a língua do outro que fez o entendimento nascer, respirar, sobreviver, se aventurar na experiência intelectual. Não foi o milagre da língua francesa, mas a intensa diferença na própria língua que fez com que os alunos conseguissem por em funcionamento aquilo de tudo está em tudo.

$\mathrm{O}$ segundo plano da descoberta de Jacotot diz respeito àquilo que se nos revela como o terceiro mandamento ou como a terceira dissonância pedagógica: traduzirás e contra-traduzirás.

Jacotot não explicou nada do francês: deu aos seus alunos um livro bilíngüe. Jacotot não pediu senão que os alunos falassem sobre o que haviam aprendido e/ou que o narrassem. Jacotot deu a possibilidade da tradução e da contra-tradução, ainda que ele próprio não o tenha feito. Ele pensou a pedagogia como uma flutuação permanente, como um fluxo e refluxo de tradução e de contra-tradução, quer dizer, imaginou o ato pedagógico como um ato de tradução de traduções. 
Mas: quem traduz e contra-traduz? Parece-me que na experiência de Jacotot tal operação é feita exclusivamente pelo outro-aluno e não pelo mestre, quem parece aguardar pacientemente ou não o resultado desse processo.

E mais ainda: traduzir e contra-traduzir para viver o irredutível de ser outro, o irredutível de cada língua ou para fazer uma tautologia da universalidade humana? Uma tradução para apagar a diferença de ser outro? Ou uma tradução onde: "cada texto é único e, simultaneamente, é a tradução de outro texto. Nenhum texto é original, pois a linguagem mesmo, na sua essência é já tradução" (Octavio Paz, 1971, p. 9)?

$\mathrm{O}$ mestre percebeu que os seus alunos não sabiam francês e ele não queria que aprendessem a sua língua numa lógica de explicação racional. Mas ele desejava que os seus alunos conhecessem a língua francesa, quer dizer, o que ele desejava era o francês e não a língua dos alunos. $\mathrm{O}$ único interesse da língua do outro era a de utilizá-la, em silêncio e na intimidade do outro, para que esses outros compreendessem o mesmo, a língua do mestre, a língua mestre.

Assim, pela pressão da igualdade - igualdade aqui no sentido de fazer convergir para o centro todas as dessemelhanças - Jacotot afastou o princípio da diferença; um princípio que consistiria em não suprimir as dessemelhanças entre as línguas, mas em fazê-las ainda mais reveladoras, mais plenas, talvez mais puras em sua diferença. Pensar a outra língua para pensar a diferença, para ter uma experiência da diferença, para ser diferentes.

$\mathrm{Na}$ interpretação de Rancière, é claro que Jacotot tinha em mente outra coisa que a diferença; tratava-se da lição da igualdade, de experiência em comum, o pensar na igualdade para ser iguais. Porém, procurando desse jeito a igualdade, o que Jacotot encontrou foi a sua invenção da alteridade.

O terceiro e último plano da descoberta é a intuição e/ou a adivinhação e/ou a certeza da compreensão da pedagogia como poética - mas não da poética como pedagogia!!

A lição dos poetas, contrariamente à lição dos gramáticos e dos oradores, é que aqueles procuram ser adivinhados e não querem comandar absolutamente nada; eles desejam ouvir e não se fazer escutar. O gramático insiste na estrutura da língua, e quer que os outros não consigam fugir dela; buscam o método onde ele talvez não exista; explicam com palavras de outros a ordem das palavras do mesmo. O orador, do outro lado, é aquela figura da língua que apaga toda possibilidade de outras vozes, não deixa nenhuma voz ser mais alta que a dele; aniquila a vontade do outro por meio de uma violenta imposição do que dizer, quando dizer, como 
dizer, porque dizer e para que dizer: "a retórica é uma palavra de revolta contra a condição poética do ser falante” (Rancière, op. cit., p. 93).

O poeta, o artista é, neste sentido, esse tradutor e contra-tradutor que Jacotot procurava como imagem do mestre emancipador. Nos termos de Rancière: "O artista tem necessidade de igualdade, tanto quanto o explicador tem necessidade de desigualdade" (idem, ibid., p. 79).

Isso significa que o mestre é criador e reflexo de uma lição embrutecedora e que o poeta, quer dizer, o artista oferece uma lição de emancipação, isto é, de relatar e fazer experimentar aos outros aquilo pelo que se é semelhante a eles.

Surge aqui uma outra dissonância, mas já não em Jacotot ou em Rancière, mas de quem é o autor deste texto.

A poética é um dar a ver, um dar a tocar, um dar a ouvir etc. Tratase de oferecer não a explicação regressiva, mas a experiência da expressão. Porém: o que se oferece é uma explicação do semelhante, do igual ou do diferente, da diferença?

Ainda mais: a pedagogia insiste em ser aquilo que nega o ver, o tocar, o ouvir. Explica o que é o ver, mas com olhos alheios, distantes, silenciosos. Explica o que é tocar, porém sem tocar. Explica o que é ouvir, mas ignorando o que é o ouvir do outro.

O que Jacotot fez, o que nós fizemos, foi fazer da pedagogia a imposição da palavra que é, que coincide com a palavra que o "eu" diz, que "eu" digo (Larrosa, 2002). O mestre ressaltou a sua palavra como uma lei que tinha que ser tanto comum quanto única, abandonando assim, em parte, a possibilidade de ser aquele mestre ignorante e de levar adiante aquela pedagogia onde: "cada ignorante pudesse se fazer, para outro ignorante, um mestre que revelaria a ele seu poder intelectual" (Rancière, op. cit, p. 72).

\section{VI}

Houve um momento, impossível de especificar no emaranhado do tempo, mas talvez nos mesmos primórdios da escolarização, no qual a vida - a nossa vida, a vida deles, a vida dos outros - escapou em sigilo da escola. Ignorada, traída e transformada em simulacro, a vida saiu da escola. Ninguém percebeu. Mas ninguém parece ter reclamado nada.

É obvio que também seria possível afirmar que a escola fugiu da vida, mas esse é um outro assunto, para mim muito menos interessante.

E quando a vida saiu da escola, já nunca mais as coisas voltaram a ser como o consenso pedagógico pretendia que fosse. $\mathrm{O}$ mestre explicador 
ocultou a sua vida por detrás de sua explicação. O aluno aprisionado ocultou a sua vida por detrás da sua aparente e efêmera compreensão. A vida, a nossa vida, acabou por estar numa outra parte, num outro lugar, longe da escola.

Foi assim que os livros que nós lemos, que eles e que os outros lêem na vida, não são já os livros que lemos na escola. Foi assim que a música que nós ouvimos, que eles e que os outros ouvem na vida, não são já a música que ouvimos na escola. E foi assim, também, que a roupa que nós vestimos, que eles e que os outros vestem na vida, não são já as roupas que vestimos na escola.

Deixamo-nos de comover na escola.

A vida foi embora da escola, e a única solução que achamos para fazêla retornar foi a de retratá-la no currículo. Fizemos séries e ciclos com a vida. Mas não vivemos a vida na escola. Nem vivemos a nossa vida, nem vivemos a vida deles, nem vivemos a vida dos outros. Não vivemos na escola.

Reformamos a vida, mas não vivemos a vida na escola.

Explicamos a vida, mas não vivemos a vida na escola.

Fazemos o simulacro de compreender a vida na escola, mas não a celebramos.

Quem sabe se $O$ mestre ignorante poderá ser um modo de fazer com que a vida volte à escola ou saia dela definitivamente.

$\mathrm{Eu}$, honestamente, ainda não o sei.

Recebido e aprovado em fevereiro de 2003.

\section{Referências bibliográficas}

DERRIDA, J. Anne Duforurmantelle invite Jacques Derrida à répondre De l'hospitalité. Paris: Calmann-Lévy, 1997.

LARROSA, J. Dar a palavra. Notas para uma dialógica da transmissão. In: Larrosa, J.; Skliar, C. (Org.). Habitantes de Babel. Políticas e poéticas da diferença. Belo Horizonte: Autêntica, 2001, p. 281-296.

PAZ, O. Traducción: literatura y literalidad. Barcelona: Tusquets, 1971. RANCIÈRE, J. O mestre ignorante. Belo Horizonte: Autêntica, 2002. 